\title{
United Nations Education Program in Space Science and Technology 1988-2018
}

\author{
Lewis Pyenson'1, Arak M. Mathai ${ }^{2}$, Hans J. Haubold ${ }^{3}$ \\ ${ }^{1}$ Department of History, Western Michigan University, Kalamazoo, MI, USA \\ ${ }^{2}$ Department of Mathematics and Statistics, McGill University, Montreal, Canada \\ ${ }^{3}$ Office for Outer Space Affairs, United Nations, Vienna International Centre, Vienna, Austria \\ Email: Lewis.pyenson@wmich.edu, a.mathai@mcgill.ca, ha ns.haubold@gmail.com
}

How to cite this paper: Pyenson, L., Mathai, A. M., \& Haubold, H. J. (2019). United Nations Education Program in Space Science and Technology 1988-2018. Creative Education, 10, 2219-2231.

https://doi.org/10.4236/ce.2019.1010160

Received: August 29, 2019

Accepted: October 20, 2019

Published: October 23, 2019

Copyright (c) 2019 by author(s) and Scientific Research Publishing Inc. This work is licensed under the Creative Commons Attribution International License (CC BY 4.0).

http://creativecommons.org/licenses/by/4.0/

\section{(c) (i) Open Access}

\begin{abstract}
Based on resolutions of the United Nations General Assembly, UN-affiliated Regional Centres for Space Science and Technology Education were established in China, India, Morocco, Nigeria, Brazil/Mexico, and Jordan. Simultaneously, education curricula at the university level were developed for the core disciplines of remote sensing, satellite communications, satellite meteorology, space and atmospheric science, and global navigation satellite systems. In 2017, these education curricula were supplemented by the publication of two open access books covering full university courses in linear algebra and probability \& statistics.
\end{abstract}

\section{Keywords}

Regional Education Centres, Education Curricula, Space and Atmospheric Science, Remote Sensing and Geographic Information System, Satellite Communications, Satellite Meteorology and Global Climate, Global Navigation Satellite Systems, Linear Algebra, Probability and Statistics

\section{Introduction}

Space science and technology education can be pursued at the elementary, secondary, and university levels. In spacefaring nations, elements of space science and technology have been introduced into science curricula at those levels. Such an innovation has not taken place in many developing countries, partly because the benefits of space science and technology have not been appreciated enough and partly because the facilities and resources for teaching space science and technology at educational institutions are not yet comprehensively developed. Education in space science and technology in industrialized countries has be- 
come highly interactive; the World Wide Web and other information technologies have become useful tools in education programs at all levels. The incorporation of elements of space science and technology into university-level science curricula can serve a dual purpose for countries. It can enable all countries to take advantage of the benefits inherent in the new technologies, which, in many cases, are spin-offs from space science and technology. It can revitalize the educational system, introduce the concepts of high technology in a non-esoteric fashion and help create national capacities in science and technology in general. In that regard, Pyenson and Sheets-Pyenson (Pyenson \& Sheets-Pyenson, 1999) emphasized in his work entitled "Servants of Nature" that:

"Both geographical decentralization and interdisciplinary innovation have become watchwords in academic science. Electronic information processing to some extent obviates the necessity for a scientist or scholar to reside at an ancient college of learning. Universities everywhere have adapted to new socioeconomic conditions by expanding curricula. They have always responded in this way, although never as quickly as their critics would like. Measured and deliberate innovation is one of academia's heavy burdens. It is also a great strength. Emerging fields of knowledge become new scientific disciplines only after they have found a secure place in universities. We look to universities for an authoritative word about the latest innovations. New scientific ideas emerge in a variety of settings, but they become the common heritage of humanity only when processed by an institution for advanced instruction like the modern university".

There are many challenges in the teaching of science at university level, in any country, but the challenges are of a higher magnitude in developing countries. The general problem confronting science education is the inability of students to see or experience the phenomena being taught, which often leads to an inability to learn basic principles and to see the relationship between two or more concepts and their practical relevance to problems in real life. Added to those problems are a lack of skills in the relevant aspects of mathematics and in problem-solving strategies. There are also language problems in countries in which science is not taught in the national language(s). Over the years, industrialized countries have overcome most of the basic problems, except perhaps a psychological problem, namely that students may consider science to be a difficult subject. In developing countries, however, basic problems linger, exacerbated by the fact that there are not enough academically and professionally well-trained teachers.

\section{Regional Centres}

Since 1988, the United Nations (United Nations General Assembly Document A/AC.105/749, 2017; United Nations General Assembly Document A/AC.105/1174, 2000), through its Program on Space Applications, supported the establishment and operation of Regional Centres for Space Science and Technology Education in Africa, Asia and the Pacific, Latin America and the Caribbean, and Western 
Asia (Agbaje, Alabi, \& Offiong, 2019; Agbaje, 2017) (Figure 1, http://www.unoosa.org/oosa/en/SAP/centres/index.html).

Regional centres were established in India (https://www.cssteap.org/) and China (http://rcssteap.org/Index/index.html) for Asia and the Pacific, in Nigeria (http://arcsstee.org.ng/home/) and Morocco (http://www.crastelf.org.ma/) for Africa, in Mexico and Brazil (http://www.crectealc.org) for Latin America and the Caribbean, and in Jordan (no website available) for Western Asia, under the auspices of the UN Programme on Space Applications.

Since 1996 the centres implement nine-month postgraduate courses in the five areas based on the model curricula that emanated from United Nations Meetings of Experts on the Development of Education Curricula for the Regional Centres for Space Science and Technology Education, held in Dundee, UK, in 1989, Granada, Spain, in 1995, and in Frascati, Italy, in 2001.

Gradually, the Regional Centre for Space Science and Technology in Asia and the Pacific, located in India, comprehensively revised and updated all education curricula to take into account advanced topics in space science and technology now teaching standard at universities around the world

(https://www.cssteap.org/information).

\section{Education Curricula}

Simultaneously, detailed education curricula at the university level were developed and published for 1) remote sensing and geographic information systems; 2) satellite communications; 3) satellite meteorology and global climate; 4) space and atmospheric science; and 5) global navigation satellite systems (positioning, navigation, timing)

(http://www.unoosa.org/oosa/en/SAP/centres/education-curriculum.html).

\section{Space and Atmospheric Science (Figure 2)}

Thousands of years ago, on a small rocky planet orbiting a modest star in an ordinary spiral galaxy, our remote ancestors looked up and wondered about their place between Earth and sky. In the twenty-first century, people ask the same profound questions about how the universe began and evolved, how people got here, where they are going and whether they are alone in the universe. After only the blink of an eye in cosmic time, those questions are beginning to be answered. In the last 40 years, space probes and space observatories have played a central role in that process. Space and atmospheric science missions and research are now generating news on a daily basis worldwide. They are responsible for programs relating to astronomy, the solar system and the Sun and its interaction with Earth. Space and atmospheric science cover everything from the middle levels of Earth's atmosphere (about 60 kilometres up) to the edge of the universe billions of light years away. It may help to understand space and atmospheric science by considering the fields that are not involved, as follows: a) Earth science programs are responsible for science relating to the Earth up to the 
Regional Centres for Space Science and Technology Education (affiliated to the United Nations)

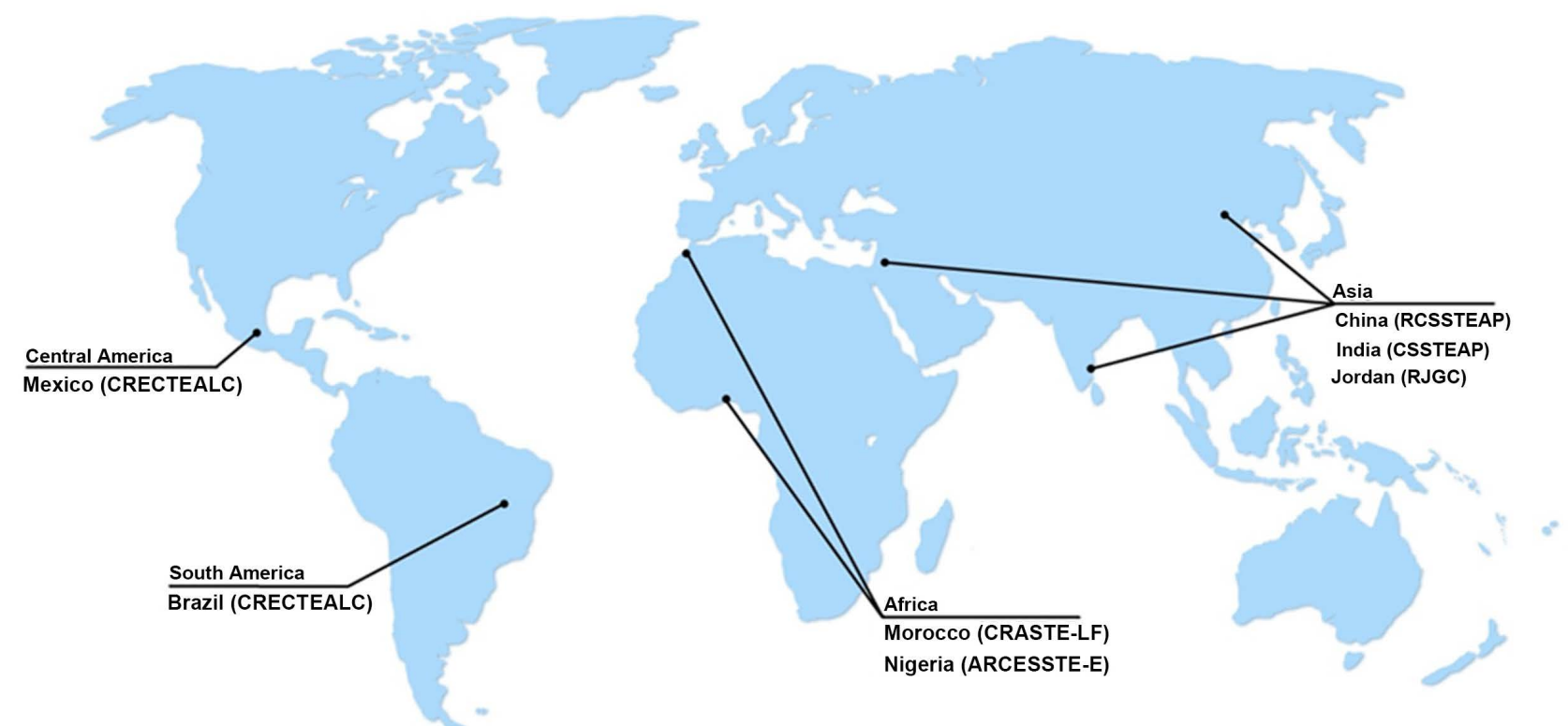

Figure 1. World map showing the geographical location of the Regional Centres for Space Science and Technology Education in four economic regions.

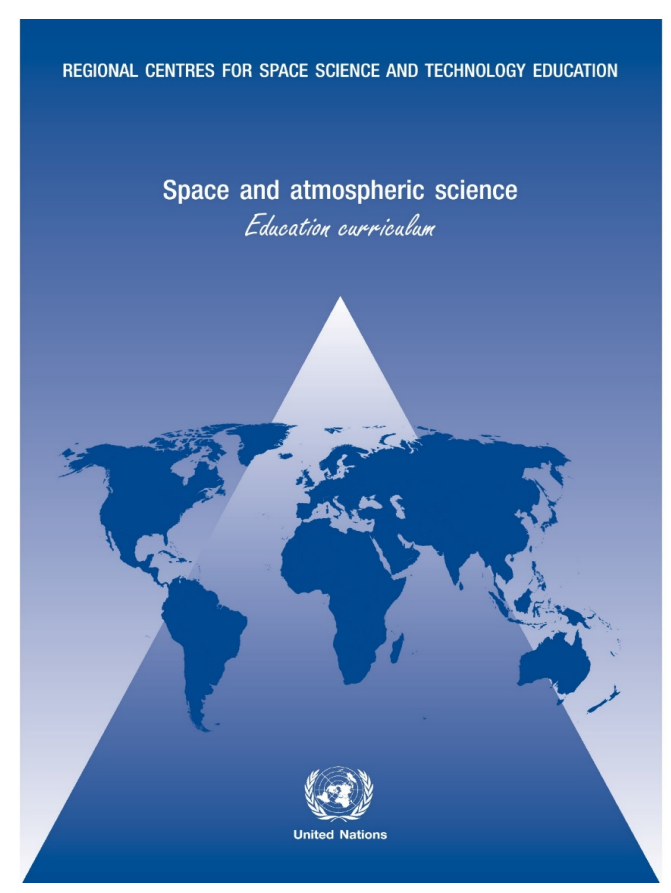

Figure 2.

http://www.unoosa.org/documents/pdf/psa/reg_centr es/curricula/Space_and_Atmospheric_Science.pdf.

middle levels of the atmosphere (about 60 kilometres up). They include topics like global warming and ozone depletion research; b) Human exploration and development in space is being addressed by manned spacecraft and space sta- 
tions. Although space and atmospheric science may use spacecraft and space stations as carriers of space experiments, it is not the primary user of those vehicles and does not involve the management of them; c) Biological and physical research programs are responsible for materials science and life science research done aboard spacecraft and space stations; d) Aerospace technology programs work on technologies for better airplanes and future launch vehicles (rockets).

\section{Remote Sensing and the Geographic Information System}

\section{(Figure 3)}

All life on Earth depends on the thin layer of gas that surrounds the globe; it is called the atmosphere, taken from the Greek word atmos (vapour) and the Latin word sphaera (sphere). Remote sensing of the atmosphere attempts to quantify numerous variables: cloud coverage and identity, water vapour concentration and precipitation rate, wind speeds, atmospheric aerosol and trace gas concentrations, and even lightning in storms. The term atmosphere has led to the creation of several other words to describe various divisions of the Earth's environmental systems:

- The hydrosphere, encompassing oceans, rivers, lakes and snow and ice on both land and sea;

- The biosphere, referring to the living things that inhabit the Earth, which for remote-sensing purposes primarily means land vegetation and oceanic phytoplankton;

- The geosphere, covering such areas as the Earth's radiation budget, the physical topography of the continents, geological processes that modify the land surface, the dynamic activity of volcanoes and the movement of the Earth's continental plates;

- The anthroposphere, meaning the influence of humanity on the surface of the Earth through structures and activity that have the potential to significantly alter the Earth's climate.

The primary processes that remote sensing seeks to measure in each of these spheres and the technical aspects of remote-sensing observations for each of these systems in terms of educational modules are described in the education curriculum.

\section{Satellite Communications (Figure 4)}

Satellite communications systems have been undergoing radical change in recent years, making a transition from a technology dominated by Governments and geostationary satellites to one that includes low-Earth orbit (LEO) and medium Earth orbit (MEO) satellite systems operated by publicly held corporations. The new systems utilize multiple antenna beams forming cells on the Earth's surface similar to those used by terrestrial cellular telephony systems and are capable of carrying various types of traffic ranging from voice to Internet traffic. Communications satellites are radio-relay stations in space. They serve much the same 


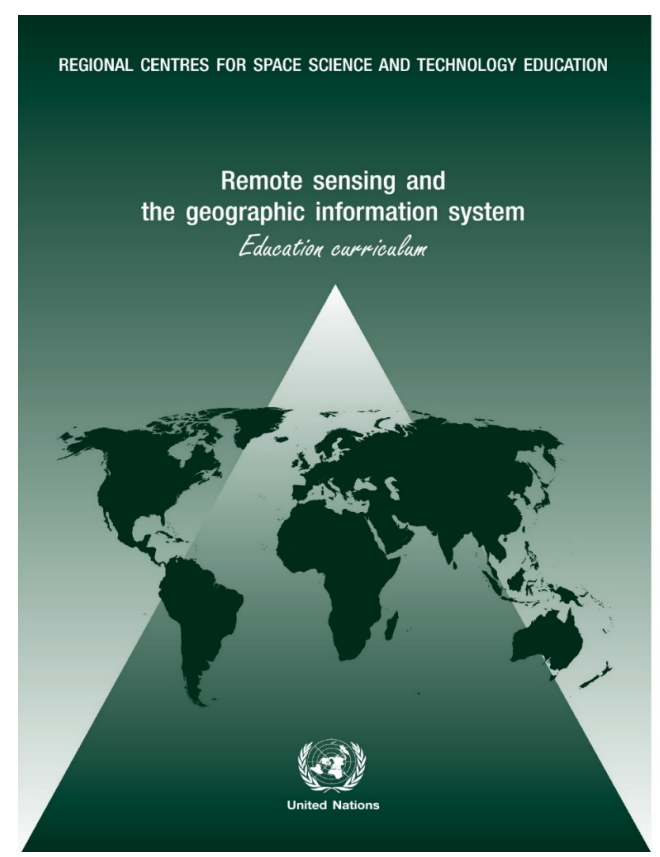

Figure 3.

http://www.unoosa.org/documents/pdf/psa/reg_ce $\underline{\text { ntres/curricula/Remote_Sensing_and_GIS.pdf. }}$

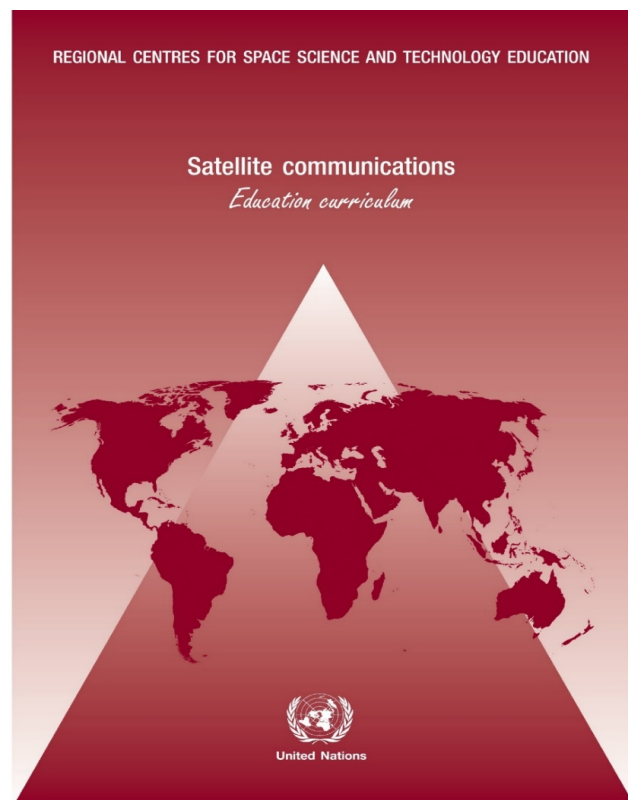

\section{Figure 4.}

http://www.unoosa.org/documents/pdf/psa/reg_c entres/curricula/Satellite_Communications.pdf.

purpose as the microwave towers seen along highways. The satellites receive radio signals transmitted from the ground, amplify them, and retransmit them back to the ground. Since the satellites are at high altitude, they can "see" across much of the Earth. This gives them their principal communications advantage: 
the ability to cover large distances of the terrain. Satellite communications systems consist of several different segments, including a space segment, a ground control segment and ground infrastructure equipment. The space segment contains the satellites, which act as nodes in space, routing the communication signal from an Earth terminal to either a final or an intermediate destination point on the Earth's surface. The ground control segment is responsible for monitoring the health and status of each satellite as well as for keeping the satellites in their appropriate locations in space. The infrastructure equipment controls the networking aspect of the entire communication system, keeping track of the duration of a communication session for billing purposes as well as assigning communication channels to the various users.

\section{Satellite Meteorology and Global Climate (Figure 5)}

Human beings have no doubt always had a fascination with and a practical interest in the weather. Meteorological phenomena were a major subject of speculation in the philosophical works of classical antiquity, but scientific study of the weather is generally dated from the invention of the thermometer and barometer in the seventeenth century. There were sporadic attempts to plot weather maps from surface observations in the eighteenth century. The invention of the telegraph in the nineteenth century opened the prospect of producing and disseminating real-time forecasts using data gathered over a large geographical area. Government-sponsored observing networks were begun in several countries in the mid- and late-nineteenth century. The nineteenth century also saw important developments in basic fluid dynamics and thermodynamics, which put the study of the atmosphere on a firm basis as a problem in applied physics. In recent decades, spectacular advances have been made in both observational and theoretical studies of the atmosphere. Such progress has been greatly facilitated by the availability of satellite platforms for atmospheric observing systems and the development of digital computers for the non-linear governing equations. Historically, the study of the atmosphere has been divided into the disciplines of meteorology and climatology. Climatology could be defined as the study of those processes that determine the time-mean state of the atmosphere, where the mean is defined as an average over a substantial period (a year or perhaps a number of years). Meteorology deals with the physics of the higher-frequency components of atmospheric variability. It has become increasingly obvious that the distinction is quite arbitrary and not particularly useful. The circulation in the atmosphere displays variability at all time scales, and there are important interactions among the various frequency components. Much recent work on atmospheric monitoring and modelling has been motivated by an awareness that humanity has the potential to alter significantly (if inadvertently) the global climate. Particular concerns have been raised about the increasing atmospheric levels of so-called greenhouse gases such as $\mathrm{CO}_{2}$ caused by industrial and agricultural activities. Reliable predictions of the sensitivity of climate to such anthropogenic 


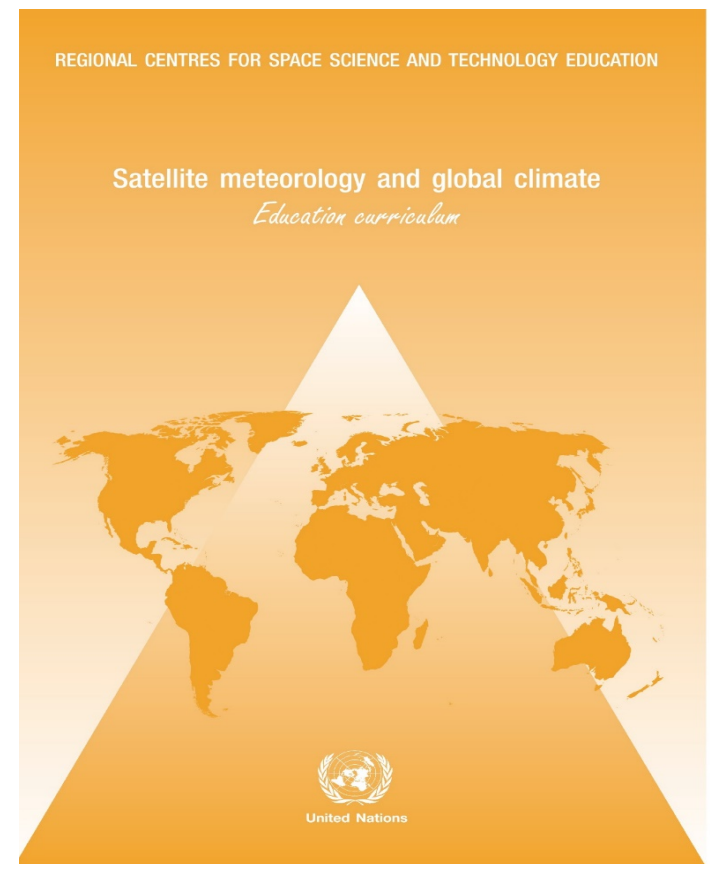

Figure 5.

http://www.unoosa.org/documents/pdf/psa/reg_centre s/curricula/Satellite_Metorology_and_Global_Climate. pdf.

influences would be enormously valuable in formulating strategies to mitigate the social and economic consequences of global environmental change.

\section{Global Navigation Satellite Systems (Figure 6)}

Satellite navigation has become a component of national infrastructure and therefore one of the pillars of modern civilization. This inevitably requires knowledgeable, skilled and competent professionals who will be able to advance, modernize, develop, and operate satellite navigation systems and their applications and services. Capacity development in the GNSS segment and attracting talented people to the field of satellite navigation has been recognized as an important subject. However, education in the satellite navigation discipline still suffers from a number of both inherited and emerging challenges.

Satellite navigation is still considered a mixture of other (mostly applied) scientific disciplines that shaped the satellite navigation through the period of its development. This leads to curricula biased towards disciplines that claim inheritance and foster particular education approach common to them. The satellite navigation community comprises professionals with various academic education backgrounds, spanning from mathematics, computer science and electronics engineering to geodesy, geography and transport and traffic sciences. While diversity should be considered and advantage rather than the opposite, significant problems arise from the fact that those specialists are still firmly anchored in the way of thinking and operation characteristic for their fundamental scientific discipline. 


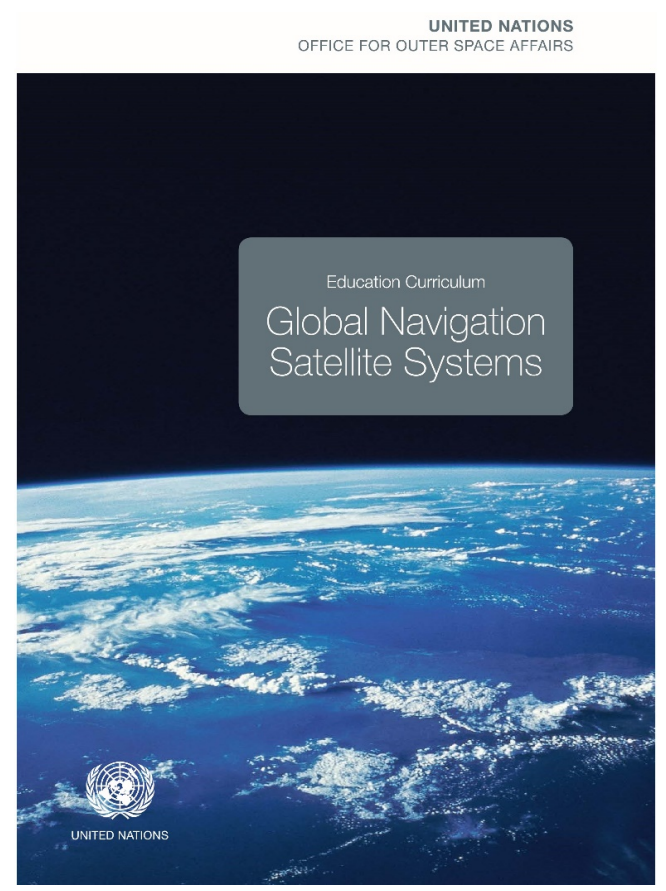

Figure 6.

http://www.unoosa.org/pdf/icg/2013/Ed_GNSS_eB ook.pdf.

Establishing satellite navigation as a separate applied science discipline with its own philosophy based on the foundations of fundamental scientific disciplines (mathematics and statistics, in particular), and new common-interest disciplines (such as computer science) will facilitate recognition of satellite navigation and allows for identification of common capacity requirements regardless of satellite navigation sub-specialization.

Satellite navigation has significantly and rather quickly changed the scope of its application. Considered a technology merger that will foster and advanced navigation, satellite navigation now encounters the fact that a majority of GNSS applications belong to the non-navigation category. Generation of massive positioning data sets that are further processed using statistical and machine learning methods to reveal the hidden patterns and knowledge, time stamping of financial transactions, taming vulnerabilities and shortcomings to create robust and resilient PNT services, synchronization of large spatially distributed networks (internet, mobile communication networks, public broadcast networks, power networks, intelligent transport systems etc.) and artificial intelligence and robotics together overtake massively the traditional navigation-related GNSS applications. Making advancements and developments in such a variety of new scenarios of usage requires new and advanced capacity in methods and techniques for statistical/machine learning, modelling, management of spatial data and computing in general.

Challenges of the kind are scientifically and intellectually attractive for talented people across the scientific disciplines. GNSS core and application 
development, and resilient GNSS development already face a shortage of professionals with the appropriate knowledge and skills, competing with numerous similar fields. However, the structured offer for academic education in satellite navigation is still sparse.

A proper GNSS academic education and professional advancement are essential for sustainable development of satellite navigation. Resolving issues related to GNSS deployment in steadily growing number of GNSS-based applications and services requires highly-capable GNSS professionals with broad knowledge and skills. Consequently, the GNSS academic education and professional advancement need a re-structuring reform that will assure the competent GNSS scientific and development community for the decades to come.

\section{Mathematics and Statistics}

To supplement all education curricula of the centres with the necessary mathematics and statistics, De Gruyter published two books (Figure 7 and Figure 8) with Open Access available on the Internet free of charge that form the basis of the mathematics foundations courses within the curricula of the centres Both are designed for physicists and engineers

(https://www.degruyter.com/dg/newsitem/256/de-gruyter-and-united-nations-c ooperate-on-open-access-book-project).

In the book titled "Linear Algebra" (Figure 7), basic properties of vectors, matrices, determinants, eigenvalues and eigenvectors are discussed. Applications of matrices and determinants to areas of statistical problems such as principal components analysis, model building, regression analysis, canonical correlation analysis, and design of experiments are examined. Applications of vector/matrix derivatives in the simplification of Taylor expansions of functions of many real scalar variables are considered. Jacobians of matrix transformations of real-valued scalar functions of matrix argument, maxima/minima problems, optimizations of linear forms, quadratic forms, bilinear forms with linear and quadratic constraints are examined. Matrix sequences and series, convergence of matrix series and applications in physical sciences, chemical sciences, social sciences, input-analysis, linear programming problem, non-linear least squares and dynamic programming problems are studied in this book.

The book titled "Probability and Statistics" (Figure 8) consists of two parts. Chapters 1 to 9 cover the topics of random experiments, sample space, probability, how to assign probabilities to individual events, random variables, expected values, statistical distributions, collections of random variables and the central limit theorem. Part 2 dealing with statistics consists of chapters 10 to 16 covering the topic of sampling distributions, point estimation, interval estimation, tests of hypotheses, prediction, regression and model building problems, design of experiments and analysis of variance, some non-parametric tests, questions and answers.

All the educational material discussed above is made available free of charge on the world-wide-web and has been implemented for teaching space science 


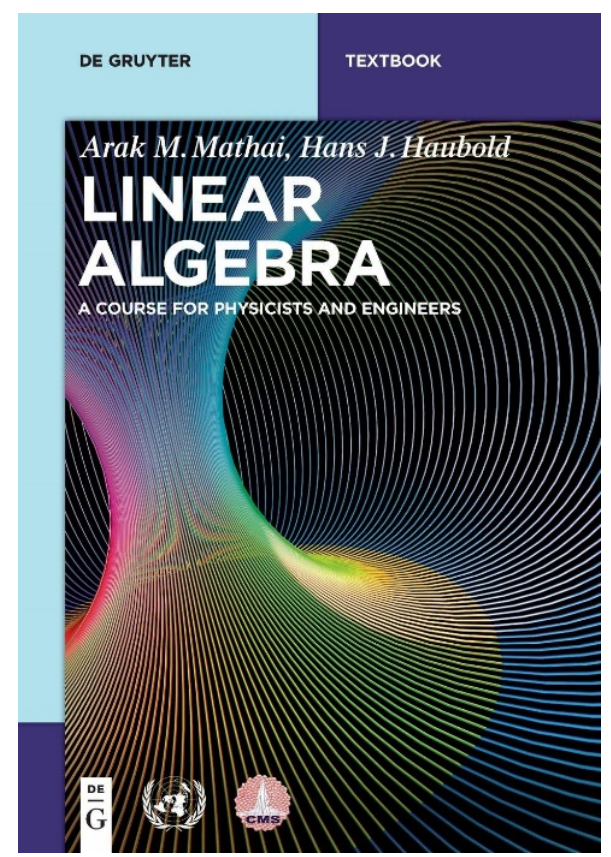

Figure 7. The book on linear algebra is available Open Access at

https://www.degruyter.com/view/product/495839.

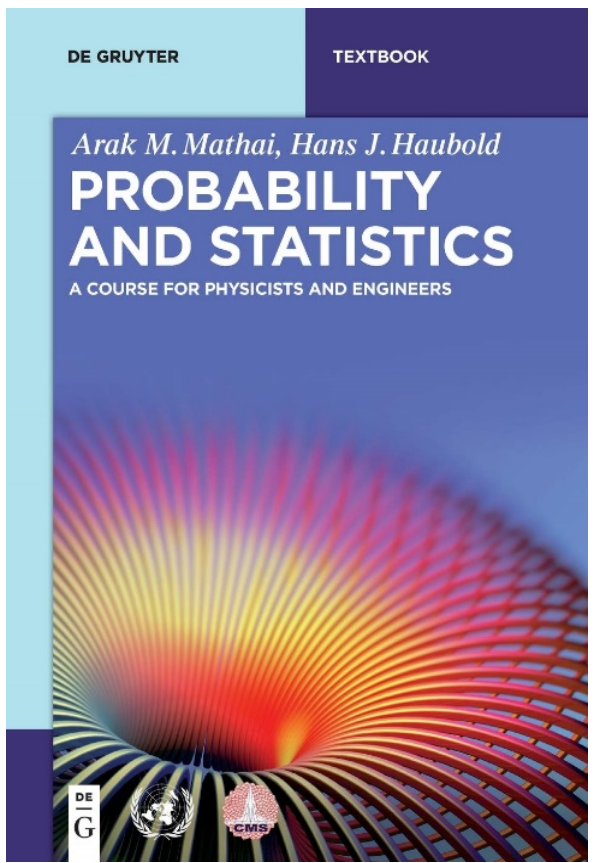

Figure 8. The book on probability and statistics is available Open Access at

https://www.degruyter.com/view/product/495845.

and technology at the centres and universities around the world and was further explored during workshops organized by the United Nations in the period of time from 1991 to 2012 (Mathai \& Haubold, 2018). 


\section{Conclusion}

Students at the UN-affiliated Regional Centres for Space Science and Technology Education have a number of advantages, among them:

1) One advantage is freedom from being confined to disciplinary units. The disciplinary walls are especially tall at many of the large and prestigious universities. People at the UN-affiliated Regional Centres may easily take full advantage of scientific ideas generated in all laboratories and institutions, even ideas from the human sciences (Humanities).

2) Another advantage is that they are not constrained by firm distinctions between practical needs and highly abstract theoretical science. As space scientists, they may freely adopt ideas and methods from engineering. This freedom is one of the signs of the past 30 years, but at many large institutions where engineering is separated from the science departments, it has been difficult to implement.

3) A third advantage is that they move between the language of the "literature" (often what is called International English) and their everyday language, which can be distinct from what they read. They are able to add new concepts and original interpretations to accepted knowledge which come from their daily experience; they see science with fresh eyes. This multilingual advantage has often appeared in the past (for example, among immigrant scientists in the Northern Hemisphere).

\section{Disclaimer}

The views expressed in this paper are solely those of the authors and do not necessarily reflect the views of any company or organization.

\section{Conflicts of Interest}

The authors declare no conflicts of interest regarding the publication of this paper.

\section{References}

Agbaje, G. I. (2017). United Nations Regional Centre for Space Science and Technology Education in Africa: Achievements, Opportunities, Challenges, and the Future. Environment and Ecology Research, 5, 386. https://doi.org/10.13189/eer.2017.050508

Agbaje, G., Alabi, O., \& Offiong, E. (2019). Education and Training in Applied Remote Sensing in Africa: The ARCSSTE-E Experinece. International Journal of Geo-Information, 8, 350. https://www.mdpi.com/2220-9964/8/8/350 https://doi.org/10.3390/ijgi8080350

Mathai, A. M., \& Haubold, H. J. (2018). United Nations Basic Space Science Initiative (UNBSSI) 1991-2012 and Beyond. Creative Education, 9, 141. https://file.scirp.org/pdf/CE_2018021215593617.pdf https://doi.org/10.4236/ce.2018.92015

Pyenson, L., \& Sheets-Pyenson, S. (1999). Servants of Nature: A History of Scientific Institutions, Enterprises, and Sensibilities. New York and London: W. W. Norton \& Company. 
United Nations General Assembly Document A/AC.105/1174 (2017).

http://www.unoosa.org/oosa/oosadoc/data/documents/2018/aac.105/aac.1051174_0.html

United Nations General Assembly Document A/AC.105/749 (2000).

http://www.unoosa.org/pdf/reports/ac105/AC105_749E.pdf 